\title{
Research on Financial Problem in Cross-border M\&A of China-funded Enterprises
}

\author{
Lu Sun \\ Shandong Yingcai University, Ji'nan, 250000, China
}

Keywords: China-funded enterprises; Cross-border M\&A; Financing problem; Countermeasures

\begin{abstract}
This paper carries out a research on the financial problem in cross-border M\&A of China-funded enterprises. Firstly, this paper briefly describes basic definition of enterprise M\&A and cross-border M\&A, and points out importance of financing in enterprise's cross-border M\&A; secondly, this paper gives a deep analysis on the financing problem in cross-border M\&A of China-funded enterprises at present, and points out the problems in financial market development, exertion of function of investment banks, and enterprise' capital structure; finally, this paper combines with the financial problem mentioned above to propose targeted measures and provides reasonable suggestions for financing problem in cross-border M\&A of China-funded enterprises.
\end{abstract}

\section{Introduction}

In recent years, China's economy is under stable development, and the achievements made at macro-economy level is delightful. Meanwhile, the government actively promotes the cross-border M\&A activities of China-funded enterprises via macro policies, which promotes the improvement of overall strength of Chinese enterprises to certain degree. Currently, China has had a batch of excellent enterprises with cross-border M\&A ability; they have good operation condition and financial level, and have the ability to carry out cross-border M\&A. Meanwhile, some entrepreneurs with long-term development eyesight also appear, and they have taken a series of significant measures for promoting the globalization and internationalization of China-funded enterprises. However, we must clearly know that the cross-border M\&A of China-funded enterprises is not as smooth as we image, and the difficult financing is the most prominent problem. This paper carries out a discussion on financing problem in the cross-border M\&A of China-funded enterprises.

\section{Enterprise M\&A and cross-border M\&A}

\section{Definition of enterprise M\&A}

As a kind of transaction activity, the enterprise M\&A refers to the activity that the enterprise adopts the form of equity transaction to release corporate right of control in order to meet its demand of foreign expansion and obtain the right of control on other company. M\&A is an main form of enterprise M\&A. Nowadays, with great economic development, M\&A has become an important means for enterprises to enhance their strength and implement strategic development.

\section{Cross-border M\&A}

While the enterprise M\&A activity is extended to worldwide, the cross-border M\&A is formed; the cross-border acquisition and merger is the main form of cross-border M\&A. In the World Investment Report of Year 2000, the UNCTAD carries out a division on cross-border M\&A; the cross-border merger refers to the behavior that the enterprise of one country and the enterprise of another country form a new legal entity through combination of assets and operation, and the cross-border acquisition refers to the behavior that the enterprise of one country obtains the control power of operation and assets of the enterprise of another country through purchasing all or partial of its stock rights or assets.

It can be known that the generic term of cross-border acquisition and cross-border merger is cross-border M\&A which refers to the behavior that the merging enterprise adopts certain channel and method of payment to purchase the stock rights or all assets of merged enterprise and then it can 
exercise business activities based on those stock rights or assets so as to control the actual or complete operation management of the merged enterprise. The cross-border mainly includes three forms, that is, horizontal, vertical, and mixed.

\section{Importance of financing condition to cross-border M\&A}

The financing condition plays an important role in cross-border M\&A, and the effectiveness of M\&A activity is influenced by financing scale, way, structure, risk, cost, enterprise preference, and other factors to a great degree, and those factors even cause a decisive influence on whether the M\&A activity can be successful. The previous M\&A financing arrangement still causes influence on cash flow, payment, and risk in development and operation after the M\&A activity is successful.

If the financing arrangement is suitable and reasonable, it can not only help enterprises to raise sufficient funds to realize M\&A objective, but also reduce the M\&A enterprise's financing cost and debt burden in future operation; after cross-border M\&A, the enterprises can reserve more resources for integration and development. While the enterprises select way of financing, if they can combine with their own features, it is able to realize the effect of getting twofold results with half the efforts; however, if the way of financing is not reasonable, the heavy debt burden may happen, and the enterprises may face the risks such as power loss.

\section{Research on financing problem in cross-border M\&A of China-funded enterprises}

China's financial market has an imperfect development and narrow financing channels.

Firstly, while the fund of financial institution enters into stock market, it shall meet the strict requirement of Chinese financial regulators. In terms of admission and investment proportion for investment of financial institution in stock market, there are strict rules stipulated in relevant laws and regulations in Chinese financial industry. In terms of first issuance, allotment, and additional issuance, Management Methods for New Securities Trades of Listed Companies, Securities Law and Company Law all propose high standard, and the equity financing conditions become very rigorous due to long approval time.

Secondly, as a kind of financing tool, the financial derivatives currently realize high development; however, in China, the main M\&A way is debt financing, and the bank loan accounts for the highest proportion. The bank loan accounted for $84.6 \%$ of total external financing in 2006 in China. Besides, there are many limitation conditions for loan; as for acquisition of M\&A loan, the investment bank shall give a guarantee or the borrowing enterprise provides pledge of assets, thus the loan is very difficult. In China's enterprise cross-border M\&A financing, the financial derivative financing tool has a low utilization rate. Some new financing tools, such as equity warrant, convertible bonds, and asset securitization, have obvious advantage; compared to common bonds, those tools have low rate of interest, and the issuing condition of contract is favorable, thus it is able to reduce enterprise financing cost to a great degree.

China's intermediary organs such as investment bank play a limited function in cross-border M\&A.

In the western enterprise M\&A, the investment bank not only serves as a financial advisor to help the enterprise to design M\&A financing scheme, arrange financing, and contact the fund supplier, but also directly serves as an investor to provide the enterprise with the fund it requires in M\&A sometimes. However, compared to western investment bank, China's current institutions which engage in the business of investment bank have narrow scope of business and weak strength, which restricts their asset operation ability and business expansion ability.

Besides, while the investment bank exerts its functions, it is restricted by many factors such as low-degree internationalization, lagging risk management level, weak legal consciousness, and shortage of professional personnel of bank, which makes the bank only play a limited function in China’s enterprise cross-border M\&A financing.

China's enterprise cross-border M\&A financing breaks away from their own capital structure and lacks of long-term planning. 
The enterprise financing cost is directly influenced by way of financing. While an enterprise selects the way of financing, it shall combine with its own capital condition. In the cross-border M\&A activity, some of Chinese enterprises lack of long-term planning and easily ignore some risks in M\&A financing, which causes the situation that the enterprise gets into trouble after M\&A. Take TCL group as an example: a series of M\&A activities it has carried out have excessive dependence on its own fund and overseas syndicated loan, thus the debt it assumes exceeds USD 1 billion, and the asset liability ratio is above $70 \%$; therefore, the enterprise seriously lacks of cash flow and the financial risk is expanded, which greatly reduces its fund-raising capacity in the capital market.

\section{Countermeasures for financing problem in cross-border M\&A of China-funded enterprises}

To perfect the construction of their own system and reasonably adjust the capital structure.

Chinese enterprises are still under development stage, and they are not mature in the construction of their own system; if they want to carry out cross-border M\&A in the international market with increasingly fierce competition, they must construct the modern enterprise system and become the economic entity which can be in line with the international market. In the cross-border $M \& A$, in order to compete with transnational corporations of developed countries and win the victory, Chinese enterprises must continuously innovate their technology and system and obtain the core competitiveness based on which they can be established in the market. With increasingly fierce competition in international market, Chinese enterprises must quicken their reform, and establish themselves as modern large-scale enterprises with first-class management, abundant capital and advanced technology so as to enhance their strength in international M\&A. Furthermore, China-funded enterprises shall also further perfect their capital structure, make full use of debt, rights and interests, mixed financing and other ways of financing to promote the realization of cross-border M\&A so as to solve the problem of high debt ratio of merged enterprises.

\section{To improve the quality of enterprise operators and investors}

As a complicated work, the cross-border M\&A involves many factors, including culture, capital, financial accounting, and risk, etc.; as for financial derivative tools, there are higher requirements in cross-border M\&A, thus Chinese enterprises’ operators and investors shall have high personal quality. However, people with internationalized capital operation capability are very deficient in China; in successful cross-border M\&A cases, most of cases are realized by virtue of consulting and financing through international financial institutions. If Chinese enterprises want to walk further on the road of cross-border M\&A, it is very necessary to cultivate more internationalized talents so that it is able to improve investors and operators' ability in cross-border M\&A.

To make full use of monetary lever and improve the utilization efficiency of bank loan

The bank loan is the most important capital source and guarantee in cross-border M\&A activity. While Chinese enterprises carry out cross-border M\&A, they can take the cross-border M\&A cases of famous enterprises in developed countries as a reference so that the M\&A financing mode they select can conform to their features. They can adopt diversified financing means to cooperate with banks; if necessary, it is able to realize the penetration of stock rights between Chinese enterprises and banking industry so as to promote tight combination of enterprise capital and bank capital and further expand the strength of Chinese enterprises in overseas M\&A activities. This kind of cooperation can effectively reduce the risk of information asymmetry, and the enterprises can also cooperate with many banks to form syndicated loan; in this way, it is able to not only meet enterprises' capital demand, but also further reduce the financing risk of banks and enterprises.

\section{To actively carry out financing by use of international capital market}

In terms of financing, it is required to obtain the support of relevant financial departments or overseas branches of domestic banks to maximum degree. In terms of overseas financing and export \&import, the banks play a fundamental function; in the cross-border M\&A, Chinese enterprises shall fully utilize the overseas branches of banks. Through the branches, the enterprises not only can obtain sufficient funds, but also can utilize the lever effect of banks, which is convenient for enterprises to utilize the financial market in host country and meet their fund demand. 
The cross-border M\&A fund or overseas investment shall be established. In order to ensure the fund demand of enterprise cross-border M\&A, it is able to let the country take the lead to establish special fund for overseas investment. Currently, China has had overseas investment fund which is managed by professional institutions; this fund carries out public financing to the society and widely absorbs the social capital, which greatly mitigates enterprise financing pressure, greatly reduces the risk of financing merely by virtue of banks, and powerfully protects enterprises' overseas capital expansion. Then, Chinese enterprises shall carry out more cooperation with overseas investment fund to realize maximum application of this financing mode.

The financing of overseas financing institutions shall be further enhanced. Except for diversified financing in China, Chinese enterprises shall also directly carry out financing in international financial market; the foreign capital market has a mature development and sufficient funds, and the gradual expansion of overseas financing can help Chinese enterprises to be further in line with international market in the cross-border M\&A, enhance the ability of resisting the risk, expand financing channels, and improve the power of economic growth.

The new financing channels shall be exploited. In the western capitalist countries, the insurance companies and pension fund can enter into capital mobilization market, thus Chinese enterprises shall actively participate in international financial market to obtain the support of those funds, which not only can expand enterprise financing channels, but also can enhance the degree of their international participation.

\section{To cultivate transnational culture and improve strategic awareness}

China shall pay further attention to cultivating transnational culture, communicating with different culture, and promoting improvement of enterprise strategic awareness. In the cross-border M\&A, Chinese enterprises shall actively know foreign culture, clearly know the operation condition of foreign financial capital, and analyze the relevant factors and financing risks of cross-border M\&A financing. Meanwhile, the Chinese enterprises shall carry out analysis on successful experience of cross-border M\&A financing from perspective of global strategic to seek for coordination of foreign relevant institutions and find a road suitable for their own cross-border M\&A financing. After completion of M\&A, the enterprises shall pay attention to follow-up integration and carry out analysis on features of fund operation under different culture states.

\section{Conclusion}

Under the condition of fierce competition at home and abroad, more and more enterprises select to improve their strength via cross-border M\&A. In this process, the powerful fund support becomes a critical factor which determines whether M\&A will be successful. The managers of China-funded enterprises shall pay attention to the financing problem which appears in cross-border M\&A activities, carefully analyze the competition situation at home and abroad, learn some experiences from foreign successful enterprises in cross-border activities, and combine with their enterprise features and advantages to use those experiences as reference. How to suitably carry out M\&A financing strategic arrangement is of critical importance for whether the M\&A can be successful; to find a suitable cross-border financing road and provide powerful fund support for cross-border M\&A has become an important difficulty before cross-border M\&A activities of China-funded enterprises.

\section{References}

[1] Liu Tao, Jian Na: Research on Financial Risks in Cross-border M\&A of Chinese Enterprises Take Wanda Group M\&A with AMC as an Example , Inner Mongolia Scientech and Economy, 2015, 03: 4-6.

[2] Li Xiaoyi: Cultural Integration Route for Cross-border M\&A Synergistic Effect, Management \& Technology of SME, vol 2, 2015, 02: 144-145. 
[3] Hong Lianying, Zhou Shunlong: Growth Mechanism of Overseas M\&A of Chinese Enterprises , Journal of Changsha University of Science and Technology (Social Science Edition), 2015, 01: 91-99.

[4] Zhou Shunlong, Hong Lianying: Analysis on Current Situation of Cross-border M\&A of Chinese Enterprises and Factors Influencing Investment - from perspective of cases in Asian region , Modern Economic Information, 2015, 03: 132.

[5] Hu Jiewu, Han Li: Macro-economic Factors and Cross-border M\&A Shareholder Wealth Effect , Journal of Beijing Jiaotong University (Social Sciences Edition), 2015, 01: 60-69. 